\title{
The Third Year Anesthesiology Residents' Knowledge Regarding Pediatric Postoperative Pain Management
}

\author{
Somboon Thienthong ${ }^{1}$, Jirawadee Seehanoo ${ }^{1}$, Wimonrat Sriraj ${ }^{1}$, Suwannee Suraseranivongse ${ }^{2}$, \\ Allen Finley ${ }^{3}$ \\ ${ }^{1}$ Department of Anesthesia, Faculty of Medicine, Khon Kaen University, Khon Kaen, Thailand; ${ }^{2}$ Department of Anesthesia, Faculty \\ of Medicine, Siriraj Hospital, Mahidol University, Bangkok, Thailand; ${ }^{3}$ Department of Anesthesia, IWK Health Center, Dalhousie \\ University, Halifax, Canada. \\ Email: somthi@kku.ac.th
}

Received September $15^{\text {th }}, 2013$; revised October $12^{\text {th }}, 2013$; accepted October $24^{\text {th }}, 2013$

Copyright (C) 2013 Somboon Thienthong et al. This is an open access article distributed under the Creative Commons Attribution License, which permits unrestricted use, distribution, and reproduction in any medium, provided the original work is properly cited.

\begin{abstract}
Background: There are six Anesthesiology training centers in Thailand that are approved to operate the training program. An evidence of residents' knowledge about pediatric postoperative pain management is needed for improving the program. Objective: To assess the third year anesthesiology residents' knowledge about pediatric postoperative pain management. Materials and Methods: The questionnaire was adapted from previous studies. The questionnaire has 35 questions consisted of 17 multiple choice questions and 18 true or false questions to cover 2 domains: 1) use of age-appropriate pediatric pain assessment (10 questions) and 2) pediatric pain treatment (25 questions). Minimal passing level of the questionnaire rated by three young anesthesiology staffs was $76.2 \%$. All 62 participants were the $3^{\text {rd }}$ year anesthesiology residents from 6 training centers. Data were analyzed by descriptive statistics. Results: The response rate was $95.2 \%$. Seventy-one percent of participants reported that they had learned about pediatric pain treatment. Of those, 55.9\% rated their remaining knowledge at median level. The proportion of the correct score was $67.7 \%$ (mean $23.7 \pm 2.9 \mathrm{SD}$ ) which was lower than the minimal passing level. The highest score was 29 and the lowest score was 16. For pain assessment domain; the mean proportion of correct score was 65\% (range 90\% - 40\%). For pain treatment domain; the mean proportion of correct score was 68.8\% (range $88 \%$ - 44\%). Conclusion: Anesthesiology residents' knowledge about pediatric postoperative pain management needs to be improved.
\end{abstract}

Keywords: Anesthesiology Resident; Knowledge; Pediatric; Postoperative Pain Management

\section{Introduction}

The Faculty of Medicine, Khon Kaen University performed 3725 cases of surgery on children and adolescent age below 20 years in 2010. It is important to provide adequate pain management to those patients as it can improve their recovery or decreases complications to avoid unnecessary prolonged hospital stay which increases the cost of treatment [1,2]. Until now, inadequate postoperative pain management for children continues to be reported in the literature. W. L. Chen [3] reported that parents and nurses also concerned about postoperative pain in children. The same concern was reported, about $45 \%$ of Canadian parents [4] and about $78 \%$ of Thai parents [5]. Among the factors influencing the outcomes of pain management, the age of children is an important one. For example, a good modality for pain relief like a patient-controlled analgesia pump could not be used by small children [6]. Another important factor is the knowledge and attitude of health care providers about postoperative pain management [7], especially anesthesiology residents who work closely with those patients. Saroyan et al. [8] reported that anesthesiology residents performed better than pediatric and orthopedic residents in answering questions related to their knowledge of acute pain management. The superior outcomes of anesthesiology residents were related to an opportunity of the directed educational programs. In 2012, there are six anesthesiology training centers in Thailand that provide education for about 60 - 70 residents every year. All these training centers have to follow the same 3-year curriculum that is controlled by the Royal College of Anesthesiology Thailand. Even so, the situation of the six centers 
may have some differences. Pain education is an example: a training center(s) with well-established acute pain service unit may provide more experiences and good knowledge to the residents. The objective of this study was to assess the third year anesthesiology residents' knowledge about pediatric postoperative pain management across the training centers in Thailand.

\section{Materials and Methods}

The protocol was approved by the ethical committee of Khon Kaen University, Thailand. This survey was done between December 2011 and August 2012. All participants were the third year anesthesiology residents in the six training centers across Thailand. The survey was conducted during the last three months of the training program to make sure that all participants had experienced all clinical areas including pediatric postoperative pain management.

The pediatric postoperative pain management questionnaire was adapted from the Pediatric Nurses' Knowledge and Attitude Survey Regarding Pain (PNKAS-P) developed by Manworren in 2001 [9] and some parts were adapted from the "assessing resident knowledge of acute pain management in hospitalized children" developed by Saroyan in 2008 [8]. The validity of the contents of questionnaires was proved by three experts in the field of pain management and it was screened by few immediate graduated anesthesiology staffs to clarify all questions.

The questionnaire has two parts: part one is about demographic of participants, e.g., gender, institution, academic training curriculum about pediatric pain management, knowledge seeking behavior and self evaluation about their knowledge; Part two is about the knowledge on pediatric postoperative pain management; there were 17 multiple choice questions and 18 true or false questions to cover 2 domains: 1 ) use of age-appropriate pediatric pain assessment (10 questions) and 2) pediatric pain treatment (25 questions). One score for one right answer and total scores were 35 .

The questionnaires were sent to the pain clinic staffs of six training centers to distribute to all the $3^{\text {rd }}$ year residents, collect and send them back to the researchers. Participants were asked to answer all questions according to their knowledge and not allowed to open any book. In case, questionnaire was not returned within one week they will receive a reminding note, a period of one month was allowed to return the last questionnaire. Data were analyzed by descriptive statistics; scores were presented as mean \pm standard deviation (SD) or percentage.

\section{Results}

Sixty-two questionnaires were sent to all $3^{\text {rd }}$ year resi- dents in the six institutes and the response rate was $95.2 \%$. The number of participants from each institution, gender, self evaluation about pediatric pain knowledge and knowledge seeking behavior were presented in Table 1. Seventy-one percent of participants from all centers stated that pain education was provided and most of them (71.4\%) recalled that they learned it in the first year of anesthesiology training program.

For the total of 35 questions, the mean correct score

Table 1. Demographic of the participants $(N=59)$.

\begin{tabular}{|c|c|}
\hline Demographic data & N (\%) \\
\hline $\begin{array}{l}\text { Institution: } \\
\quad \text { CU }\end{array}$ & 10 (16.9) \\
\hline $\mathrm{RH}$ & $9(15.2)$ \\
\hline SH & $24(40.7)$ \\
\hline KU & $7(11.9)$ \\
\hline $\mathrm{CU}$ & $8(13.6)$ \\
\hline SU & $1(1.7)$ \\
\hline Male:Female & $14: 45(23.7: 76.3)$ \\
\hline \multicolumn{2}{|c|}{$\begin{array}{l}\text { Level of knowledge about pediatric pain } \\
\text { management by self evaluation: }\end{array}$} \\
\hline Low & $23(39.0)$ \\
\hline None & $3(5.1)$ \\
\hline \multicolumn{2}{|c|}{$\begin{array}{l}\text { Pediatric pain management was taught in the } \\
\text { anesthesiology training curriculum: }\end{array}$} \\
\hline No & $17(28.8)$ \\
\hline \multicolumn{2}{|c|}{$\begin{array}{l}\text { Academic year which teaching pediatric pain } \\
\text { management: }(\mathrm{N}=42)\end{array}$} \\
\hline $2^{\text {nd }}$ year & $11(26.2)$ \\
\hline $3^{\text {rd }}$ year & $1(2.4)$ \\
\hline \multicolumn{2}{|l|}{$\begin{array}{l}\text { Seeking behavior for pediatric pain } \\
\text { management from other sources: }\end{array}$} \\
\hline No & $9(15.2)$ \\
\hline $\begin{array}{l}\text { Source of learning: } \\
\text { Staffs }\end{array}$ & 30 (50.9) \\
\hline Text book & 33 (55.9) \\
\hline Internet & $24(40.7)$ \\
\hline Conferences & $6(10.2)$ \\
\hline Others & $2(3.4)$ \\
\hline $\begin{array}{c}\text { Frequency of knowledge seeking ab } \\
\text { pediatric pain management: } \\
\text { High (Every } 2 \text { - } 3 \text { week) }\end{array}$ & $3(5.1)$ \\
\hline Modest (Every month) & $18(30.5)$ \\
\hline Seldom (More than a month) & $38(64.4)$ \\
\hline
\end{tabular}


was $23.7 \pm 2.9$ (67.7\%). The highest score was 29 and the lowest score was 16 . The proportion of participants who had correct answer for each question was presented in Table 2.

Table 2. The proportion of participants who had correct answer for each question $(\mathrm{N}=59)$.

\begin{tabular}{cl}
\hline Questions & $\begin{array}{l}\text { Number } \\
\text { of correct Percent } \\
\text { answer }\end{array}$ \\
\hline
\end{tabular}

\section{The first domain}

1 Observable changes in vital signs must be relied upon to verify a child's/adolescent's statement that he has severe pain

2 Because of an underdeveloped neurological system, children under 2 years of age have decreased pain sensitivity and limited memory of painful experiences

3 If the infant/child/adolescent can be distracted from his pain this usually means that he is not experiencing a high level of pain

4 Infants/children/adolescents may sleep in spite of severe pain

5 Comparable stimuli in different people produce the same intensity of pain

6 Children less than 8 years cannot reliably report pain intensity and therefore, the nurse should rely on the parents' assessment of the child's pain intensity

7 A three-year-old child, who is developmentally normal, is in the postoperative care unit following a tonsillectomy. She is awake and alert. The mother states that her child is in pain. What is the best measure of this child's pain?

8 A one-year-old child had surgery on her stomach. Her face looks grimace with occasional restless and tense, get improved after hugging. Her FLACC score is:

9 The most accurate judge of the intensity of the child's/adolescent's pain is

10 Which of the following describes the best approach for cultural considerations in caring for child/adolescent in pain:

\section{The second domain}

11 Non-drug interventions (e.g. heat, music, imagery, etc.) are very effective for mild-moderate pain control but are rarely helpful for more severe pain

12 Children who will require repeated painful procedures (ie. Daily blood draws), should receive maximum treatment for the pain and anxiety of the first procedure to minimize the development of anticipatory anxiety before subsequent procedures

13 Respiratory depression rarely occurs in children/adolescents who have been receiving opioids over a period of months

14 Acetaminophen $650 \mathrm{mg}$ per oral is approximately equal in analgesic effect to codeine 32 mg per oral

\section{Continued}

15 The World Health Organization (WHO) pain ladder suggests using single analgesic agents rather than combining classes of drugs (e.g. combining an opioid with a non-steroidal agent)

16 The usual duration of analgesia of Morphine IV is $4-5$ hours

17 Parents should not be present during painful procedures

18 Adolescents with a history of substance abuse should not be given opioids for pain because they are at high risk for repeated addiction.

19 Young infants, less than 6 months of age, can not tolerate opioids for pain relief

20 Anxiolytics, sedatives, and barbituates are appropriate medications for the relief of pain during painful procedures

21 After the initial recommended dose of opioid analgesic, subsequent doses should be adjusted in accordance with the individual patient's response

22 The child/ adolescent should be advised to use non-drug techniques alone rather than concurrently with pain medications

23 The maximum accepted daily dose of Ketorolac for a school-age child is:

24 The maximum accepted daily dose of metoclopramide (IV.) for a school-age child is:

25 NSAIDs that not recommended for using in children is:

26 The recommended route of administration of opioid analgesics to children with severe postoperative pain is

27 The recommended route of administration of opioid analgesics to children with brief, severe pain of sudden onset, e.g. trauma or postoperative pain, is

28 Which of the following analgesic medications is considered the drug of choice for the treatment of moderate to severe postoperative pain

29 Which of the following IV doses of morphine administered would be equivalent to15 $\mathrm{mg}$ of oral morphine

30 Analgesics for post-operative pain should initially be given

31 The most likely explanation for why a child/ adolescent with pain would request increased doses of pain medication is

32 Which of the following analgesic medications can be regularly used for the treatment of postoperative pain

33 Which of the following is the most effective treatment modalities for upper abdominal surgery

34 You wish to administer morphine sulfate $4 \mathrm{mg}$ by intravenous (IV) push. Morphine is not immediately available but pethidine is. The equianalgesic dose of pethidine IV is:

35 An appropriate dose of morphine to mix with $0.08 \%$ bupivacaine solution for continuous epidural infusion in $50 \mathrm{~kg}$ children is: 
For 10 questions about the use of age-appropriate pediatric pain assessment domain, the mean correct score was 6.5 (65\%). The highest score was 9 (90\%) and the lowest score was 4 (40\%). There were 3 questions from this domain that less than $50 \%$ of participants gave correct answers.

For 25 questions about the pediatric pain treatment domain; the mean correct score was 17.2 (68.8\%). The highest score was 22 (88\%) and the lowest score was 11 (44\%). There were 5 questions from this domain that less than $50 \%$ of participants gave correct answers.

\section{Discussion}

Children's pain is often underestimated and undertreated. Our previous survey found that pediatric health care providers in the Northeastern Thailand needed to improve their knowledge and skills about pediatric pain management [10]. It is common that knowledge and skills gradually decrease after learning something, especially, when the knowledge is not integrated into practice. Therefore, adequate knowledge and skills about pediatric pain management are necessary for anesthesiology residents before their graduation. Although many numbers of questions in this study were adapted from the nurses' knowledge and attitudes regarding pediatric pain [9], those questions were the general knowledge and were integrated well in the questionnaire. Thus, it is appropriate to use those questions to evaluate any pediatric care providers' competency in pain management. In the present study, $71 \%$ of the participants from 6 centers recalled that pain education was provided during the anesthesiology training program. In addition to the training program, about $50 \%$ of the residents continued their self-study either by reading books (55.9\%), internet based learning $(40.7 \%)$ or other ways. The level of knowledge evaluated by the residents themselves was modest and was correlated with the mean correct score $(67.7 \%)$ of the test.

The present study assessed only the anesthesiology residents' knowledge but not compared with that of the residents in other disciplines. Saroyan et al. [8] assessed pediatric pain knowledge among 3 residency training programs and found that anesthesiology residents had better knowledge compared to orthopedic or pediatric residents. The mean correct score of anesthesiology residents in the present study was not different from the study on radiotherapy residents done by Porzio et al. [11] in 2005 (67.7\% vs 63.7\%). Although the questionnaire in their study had less number of items compared to the present study (16 items vs 35 items) and they had only 3 questions that specific to pediatric pain management. Hameedand Sweedan [12] assessed the knowledge of 101 pediatric resident doctors in 3 training centers in Baghdad about neonatal pain and found that knowledge is increasing by the year of training $\left(21.7 \%\right.$ in the $1^{\text {st }}$ year, $55.2 \%$ in the $2^{\text {nd }}$ year and $57.1 \%$ in the $3^{\text {rd }}$ year) but their knowledge was still inadequate when compared to other studies in developing countries [13,14].

There were 8 questions in the present study that the correct answer was given by less than $50 \%$ of participants. The reasons for this poor performance were not clear because it might be related to the questions themselves (difficult questions or unclear questions) or related to students' factor or other factors. We knew that all 6 training centers had both pain specialists and pediatric anesthesia specialists to contribute to give knowledge for their residents. If the training program provides more time for residents to rotate in the pediatric area, the quality of knowledge about pediatric postoperative pain management would be improved further.

A know-do gap of physicians was another aspect that should be concerned because it played a major role in pediatric pain management. The present study did not assess directly about attitudes and practices of the residents. In the previous study by V. R. Breakey et al. [15], the attitudes and practices for analgesia and sedation during lumbar puncture to pediatric patients were compared between pediatric residents and emergency medicine residents, and they found that pediatric residents used less injectable local anesthetic and used more sedation for lumbar puncture than did emergency medicine residents.

There were some limitations in the present study: firstly, one of the six training centers, there was only one $3^{\text {rd }}$ year resident. Therefore his score might not represent a real mean score of that center. Secondly, the questionnaires were evaluated for content validity and did a few cases pilot surveys but the coefficient of validity was not calculated. The reasons to explain 8 questions with low proportion of correct answer remain unclear and may require further modification.

In conclusion, Pain education has been provided during Anesthesiology training programs in Thailand. However, the third year anesthesiology residents' knowledge about pediatric postoperative pain management needs to be improved.

\section{Acknowledgements}

The authors would like to thank anesthesiology residents who had participated in this survey, pain clinic staffs whose supported data collection and Professor Yukifumi Nawa for assistance in manuscript preparation. This researchwas made possible by a Teasdale-Corti Team Grant from the Global Health Research Initiative, administered by the International Development Research Centre (IDRC), Canada.

\section{REFERENCES}

[1] F. Bonnet and E. Marret, "Postoperative Pain Manage- 
ment and Outcome after Surgery,” Best Practice \& Research Clinical Anaesthesiology, Vol. 21, No. 1, 2007, pp. 99-107. http://dx.doi.org/10.1016/j.bpa.2006.12.007

[2] M. L. Peters, M. Sommer, M. van Kleef and M. A. Marcu, "Predictors of Physical and Emotional Recovery 6 and 12 Months after Surgery,” 2011. http://onlinelibrary.wiley.com

[3] W. L. Chen, “Nurses' and Parents’ Attitudes toward Pain Management \& Parental Participation in Postoperative Care of Children,” 2011. http://eprints.qut.edu.au/16127/

[4] N. Sikich, A. S. Carr and J. Lerman, "Parental Perceptions, Expectations and Preferences for the Post-Anaesthetic Recovery of Children,” Pediatric Anesthesia, Vol. 7, No. 2, 1997, pp. 139-142. http://dx.doi.org/10.1046/j.1460-9592.1997.d01-62.x

[5] W. Krisanaprakornkit, W. Chaiwong, M. Thananan, R. Khamhom and D. Nonlaopol, "Parental Requirements for Peri-Operative Information in Srinagarind Hospital," 64th Annual Meeting, Royal College of Anesthesiologists of Thailand, Bangkok, 20 August 2006, p. 19.

[6] C. L. Monitto, R. S. Greenberg, S. Kost-Byerly, et al., "The Safety and Efficacy of Parent-/Nurse-Controlled Analgesia in Patients Less than Six Years of Age," Anesthesia \& Analgesia, Vol. 91, No. 3, 2000, pp. 573-579. http://dx.doi.org/10.1213/00000539-200009000-00014

[7] A. Twycross and A. Williams, "Establishing the Validity and Reliability of a Pediatric Pain Knowledge and Attitudes Questionnaire,” Pain Management Nursing, Vol. 14, No. 3, 2011, pp. E47-E53. http://dx.doi.org/10.1016/j.pmn.2011.03.001

[8] J. M. Saroyan, W. S. Schechter, M. E. Tresgallo, et al., "Assessing Resident Knowledge of Acute Pain Management in Hospitalized Children: A Pilot Study," Journal of Pain and Symptom Management, Vol. 36, No. 6, 2008, pp. 628-638.

http://dx.doi.org/10.1016/j.jpainsymman.2007.12.006
[9] R. C. Manworren, "Development and Testing of the Pediatric Nurses' Knowledge and Attitudes Survey Regarding Pain,” Pediatric Nursing, Vol. 27, No. 2, 2011, pp. 151-158.

[10] P. A. Forgeron, D. Jongudomkarn, J. Evans, G. A. Finley, S. Thienthong, P. Siripul, et al., "Children's Pain Assessment in Northeastern Thailand: Perspectives of Health Professionals," Qualitative Health Research, Vol. 19, No. 1, 2009, pp. 71-81.

[11] G. Porzio, M. Valenti, F. Aielli, L. Verna, F. Narducci, M. Valeriani, et al., "Pain Evaluation and Management: A Survey of Italian Radiotherapists," Supportive Care in Cancer, Vol. 13, No. 4, 2005, pp. 215-218. http://dx.doi.org/10.1007/s00520-004-0687-1

[12] N. N. Hameed and B. H. Sweedan, “Assessment of Knowledge of Pediatric Resident Doctors about Neonatal Pain,” The Iraqi Postgraduate Medical Journal, Vol. 11, No. 4, 2012, pp. 443-452.

[13] P. Heaton, D. Herd, A. Fernando, D. Herd and A. Fernand, "Pain Relief for Simple Procedures in New Zealand Neonatal Units Practice Change over Six Years,” Journal of Paediatrics and Child Health, Vol. 43, No. 5, 2007, pp. 394-397. http://dx.doi.org/10.1111/j.1440-1754.2007.01086.x

[14] P. H. Gray, J. A. Trotter, P. Langbridge and C. V. Doherty, "Pain Relief for Neonates in Australian Hospital: A Need to Improve Evidence-Based Practice," Journal of Paediatrics and Child Health, Vol. 42, No. 1-2, 2006, pp. 10-13.

http://dx.doi.org/10.1111/j.1440-1754.2006.00782.x

[15] V. R. Breakey, J. Pirie and R. D. Goldman, "Pediatric and Emergency Medicine Residents' Attitudes and Practices for Analgesia and Sedation during Lumbar Puncture in Pediatric Patients,” Pediatrics, Vol. 119, No. 3, 2007, pp. E631-E636. http://dx.doi.org/10.1542/peds.2006-0727 